\title{
1 Natural hazards in Australia: floods
}

2

3

4

5

6

7

Fiona Johnson ${ }^{1 *}$, Christopher J. White ${ }^{2,3}$, Albert van Dijk ${ }^{4}$, Marie Ekstrom ${ }^{5}$, Jason P. Evans ${ }^{6}$, Dörte Jakob $^{7}$, Anthony S. Kiem ${ }^{8}$, Michael Leonard ${ }^{9}$, Alexandra Rouillard $^{10}$, Seth Westra ${ }^{9}$

1. UNSW Water Research Centre, School of Civil and Environmental Engineering, UNSW Australia 2. School of Engineering and ICT, University of Tasmania, Australia

3. Antarctic Climate and Ecosystems Cooperative Research Centre, University of Tasmania, Australia 4. Fenner School of Environment \& Society, Australian National University, Australia 5. Land and Water, Commonwealth Science and Industrial Research Organisation, Australia 6. Climate Change Research Centre \& ARC Centre of Excellence for Climate System Science, UNSW, Australia

7. Environment and Research Division, Bureau of Meteorology, Australia

8. Centre for Water, Climate and Land Use (CWCL), Faculty of Science and IT, University of Newcastle, Australia 9. School of Civil, Environmental and Mining Engineering, University of Adelaide, Australia 10. School of Plant Biology, The University of Western Australia, Australia

*Corresponding Author:

Fiona Johnson

Email:f.johnson@unsw.edu.au 


\section{Abstract}

29 Floods are caused by a number of interacting factors, making it remarkably difficult to explain 30 changes in flood hazard. This paper reviews the current understanding of historical trends and 31 variability in flood hazard across Australia. Links between flood and rainfall trends cannot be made due to the influence of climate processes over a number of spatial and temporal scales as well as landscape changes that affect the catchment response. There are also still considerable uncertainties in future rainfall projections, particularly for sub-daily extreme rainfall events. This is in addition to the inherent uncertainty in hydrological modelling such as antecedent conditions and feedback mechanisms. Research questions are posed based on the current state of knowledge. These include a need for high-resolution climate modelling studies and efforts in compiling and analysing databases of subdaily rainfall and flood records. Finally there is a need to develop modelling frameworks that can deal with the interaction between climate processes at different spatio-temporal scales, so that historical flood trends can be better explained and future flood behaviour understood. 


\section{1. Introduction}

44 Floods are one of the most dangerous natural hazards worldwide, with thousands of people dying and hundreds of millions of dollars damage on average per event (Guha-Sapir et al. 2015). Particularly significant flood events can cost much more; for example the Queensland 2010-2011 floods caused over \$AUD2 billion infrastructure damage and even larger indirect costs to the economy. To better manage flood risk in the future, it is necessary to know whether and how flood magnitude and frequency is changing. Although the annualised total cost of floods has been increasing over time in Australia (e.g., Guha-Sapir et al. 2015), it is unclear whether the trends are due to changes in reporting mechanisms, population, land use, infrastructure, and/or in the frequency and magnitude of flood causing mechanisms. The limited assessments that have been conducted directly on trends in Australian flood data have suggested that, if anything, the magnitude of floods has remained unchanged or even decreased in many parts of the country (Ishak et al. 2013). The reasons for these changes are not fully understood.

Explaining changes in flood hazard is challenging because of the interactions between meteorological and catchment conditions. Floods are primarily caused by intense rainfall events on site or upstream, but are also influenced by the location, pattern and duration of the rainfall event, the overall catchment wetness prior to the event, and the hydraulic characteristics of the catchment. Furthermore, most inhabited catchments in Australia have been anthropogenically modified.. To attribute changes in flood behaviour to one or more causes requires a deep understanding of the nature, timing and extent of these various influences. The presence of long-term natural variability in the climate system (Kiem et al. 2003), as well as anthropogenic climate change (CSIRO and Bureau of Meteorology 2015), adds to the difficulties in attributing changes in floods to any one cause or combination of several causes. Despite this, understanding future flood hazard is important to prioritise future investment in infrastructure, floodplain management practices and resources for operational flood forecasting. 
This paper is part of the Special Issue on changes to natural hazards in Australia, and describes our present understanding of the causes of floods in Australia, how flood hazard has changed over time and how it is projected to change in the future. The paper also presents a number of open research questions that should be prioritised to better understand historical and future change to Australian flood hazard.

\section{Understanding floods}

\subsection{Defining flood types and hazards}

Beyond the broad definition of 'unwanted water covering otherwise dry land', there is no universal taxonomy for floods. A prominent distinction is between coastal floods caused by high tides, storm surge and strong winds, and fluvial floods caused by rainfall and possibly snowmelt (Blöschl et al. 2015). The primary driver of fluvial floods in Australia is heavy rainfall, although the rainfall itself does not need to be extreme to lead to an extreme flood impact (Leonard et al. 2014). Coastal hazards are the subject of a companion paper in this Special Issue (McInnes et al., this issue), whilst the hazards from tropical cyclones and storms are discussed in Walsh et al. (this issue).

Another important distinction in flood classification is their temporal and spatial scale.. Flash floods can occur anywhere in the landscape but are normally limited to relatively small catchments (Blöschl et al. 2015; Hapuarachchi et al. 2011). Widespread floods are generally due to prolonged rainfall or sequential large events and are generally related to larger-scale circulation patterns such as extratropical cyclones. Flooding can also be related to longer timescale variations in atmospheric and oceanic states (Kiem et al. 2003). This paper focuses on fluvial floods and explores their relationship to the climatic and meteorological mechanisms that generate such events.

Flood hazard is generally defined in terms of the magnitude and probability of occurrence. Flood magnitude is often quantified in terms of peak streamflow, but other measures include rate of flow or water level increases, flow velocity, and area or duration of inundation.. In a design context, Australian Rainfall and Runoff (Engineers Australia 1987) provides guidance on best-practice 
methods for flood estimation, which depend on the frequency of the event. In an operational setting in Australia, flood magnitude is reported as a relative flood severity (minor, moderate or major), by comparing the flood height to pre-specified thresholds at forecast locations. The focus of this review is peak streamflow magnitude because this is the most commonly available information.

\subsection{Causes and mechanisms of flood hazard}

When trying to understand how changes to the climate affect flood hazard, it is necessary to account for processes across a wide range of timescales depicted in Figure 1. There are differences in the timescales of the rainfall event itself $\left(T_{p}\right)$ compared to the flood hydrograph $\left(T_{Q}\right)$; this difference can be particularly pronounced in the catchments west of the Great Dividing Range in Australia where flood events take the order of months to flow along the Darling River. Geological influences (Gaál et al. 2012) lead to variations in floodplain extent and nature of the flood hazard, and hence the population affected. Landforms and soil affect antecedent conditions; this is further explored in Figure 2. Figure 1 also shows that geological timescales affect the type and occurrence of rainfall events e.g. strong orographic rainfall around Coffs Harbour on the east coast leads to a high risk of flash flooding. Shown at the top of Figure 1 are the important global climate patterns (e.g., El Niño/Southern Oscillation (ENSO), Southern Annular Mode (SAM), Interdecadal Pacific Oscillation (IPO)) that have a strong influence on inter-annual, annual and seasonal variations in the occurrence and magnitude of floods (e.g., see Westra et al. this issue). In addition, these large-scale climate patterns can control synoptic-scale meteorological processes as reviewed in Walsh et al. (this issue).

There are significant regional variations in flood-producing meteorological processes around Australia; a review of Australian rainfall variability is provided in Risbey et al. (2009). Other mechanisms include East Coast Lows in the south-east (Callaghan and Power 2014), tropical cyclones in the north or more generally thunderstorms, the latter particularly relevant to flash flooding (McKay 2007). The challenge is how to attribute observed flood trends to either large scale mechanisms or the rainfall processes that can occur locally over very short timescales, or both. 
A catchment's runoff generating mechanisms also play a major role in determining how changes to extreme rainfall will be translated into changes in flood hazard. Two important mechanisms infiltration excess and saturation excess runoff - are responsible for a significant portion of flood runoff in Australian catchments (Figure 2). The saturation excess mechanism is more common in humid catchments with relatively high water tables or wet antecedent conditions (Figure 2a). The event rainfall is shown in Figure $2 a$ increases the extent of saturated land. The infiltration-excess mechanism (Figure $2 \mathrm{~b}$ ) is likely to apply in situations where the instantaneous rainfall intensity is significantly higher than the hydraulic conductivity of the soil (Mirus and Loague 2013). Trancoso et al. (2016) classify 355 catchments in eastern Australia according to climate and runoff mechanisms and such an approach could be extended to consider flood generation as well. Both mechanisms affect the relative importance of extreme rainfall compared to the antecedent moisture conditions. As shown in Figure 2, in both cases catchment evapotranspiration prior to the flood also has a large impact on antecedent conditions. Potential future changes to evapotranspiration are discussed in Kiem et al. (this issue). Thus, flood hazard can depend both on the longer-term water balance that determines antecedent catchment wetness and groundwater levels, as well as the intensity of the rainfall event.

\subsection{Modelling floods}

Due to the complexity of flood-generating processes and data limitations it is necessary to make simplifying assumptions when estimating flood hazard Where streamflow data are available, a flood variables and flood hazard, preventing extrapolation under changing catchment and/or climate conditions.. 
When streamflow observations are not available the flood hazard must be estimated using rainfallrunoff models. A common modelling approach uses design rainfalls (i.e., rainfall estimates from Intensity-Frequency-Duration relationships) in a hydrologic model of the catchment (Engineers Australia 1987). The most popular design flood models used in Australia tend to be used with a simple loss model similar to the infiltration-excess mechanism, although as shown in Figure 2 the saturation excess mechanism controls runoff in many catchments. The resulting hydrographs are used directly to estimate flood hazard or in a hydraulic model to estimate velocities and inundation extents. Alternatively, a continuous simulation approach can be adopted using long time series of

\subsection{Historical changes to floods}

\section{Historical changes to floods and causative variables}

The most comprehensive study on historical trends in floods in Australia to date (Ishak et al. 2013) considered annual maximum series (AMS) of instantaneous streamflow data from 330 catchments across the country with minimal regulation or land cover change. The directions of trends in the AMS were found to be mixed (i.e., both decreasing and increasing), although only $30 \%$ of stations had significant trends ( $10 \%$ level). Many more stations had decreasing trends rather than increasing ones. Most of the decreasing trends were found along the eastern and south-eastern coasts, 
although it is important to note that this is also where the vast majority of stations used in the analyses are located. Ishak et al. (2013) also restricted the analysis period to exclude the multi-year Millennium Drought (2001-2009), which reduced by about half the number of locations with significant decreasing trends. Some of the significant trends were also removed when the statistical tests were conditioned on SAM, ENSO and IPO, highlighting the influence of large-scale climate variability on extremes. However these indices themselves may have some covariation with longterm warming trends..

Given that the average record length used by Ishak et al. (2013) was only 38 years, this demonstrates the difficulty in separating non-stationarity related to anthropogenic climate change from that associated with natural low frequency climate oscillations. Although there was considerable quality (Rouillard et al. 2015).

There has been more research into inter-annual and multi-decadal variability than trend analyses for floods in Australia. A recent global analysis of floods (Ward et al. 2014) shows that flood volumes are significantly higher than average in the north-west and arid inland Australia during La Niña years and 
The high variability in Australia's climate, coupled with the low population density, means that highquality, long-term streamflow gauge records are relatively rare. The value of maintaining these networks in the face of funding pressure has been demonstrated by Cordery (2003). The inability to separate long-term trends from climate mode variability is directly attributable to the relatively short streamflow records and, despite many advances in the last decade, still quite limited understanding into what role the climate modes play in relation to flood hazard (and also a lack of long-term information about the climate modes). Modelling studies may be useful to supplement this gap given that rainfall records are generally longer and provide better coverage of the continent. Examples include CSIRO's Sustainable Yields projects ${ }^{1}$ which have covered large parts of Australia. However, the focus of these projects was on long-term yield rather than floods and the opportunity to use the modelling to examine trends and variability over the historical period was not fully capitalised, pointing at a promising opportunity.

\subsection{Historical changes to extreme rainfall}

Increases in the proportion of heavy rainfall have been detected across Australia with heavy daily rainfall accounting for an increased proportion of total annual rainfall since the 1970s (CSIRO and Bureau of Meteorology 2015). Regionally, however, significant variability exists. Gallant et al. (2007) found that the proportion of total rainfall stemming from extreme events has increased since the 1950s along the eastern coast and in south-western Australia, and since the 1970s in the south-east.

Observed trends in extreme rainfall across much of Australia have been consistent with mean rainfall trends, although trends in the extremes have typically been greater than the mean trend (Alexander et al. 2007); that is, where average rainfall is increasing, the extremes have tended to increase at a faster rate. The north-west of Australia has been relatively wet during the late 20th century, with increases in rainfall and the frequency of extreme rainfall events over the monsoonal and sub-tropical north-west, particularly during summer (Evans et al. 2014; Shi et al. 2008). Other

\footnotetext{
${ }^{1}$ http://www.csiro.au/en/Research/LWF/Areas/Water-resources/Assessing-water-resources/Sustainableyields
} 
studies have considered non-stationarity in extreme rainfalls for single sites (Jakob et al. 2011a;

Yilmaz and Perera 2013) or small collections of stations (Jakob et al. 2011b; Laz et al. 2014). In general these studies have found that rainfall extremes for short duration events tend to have increasing trends. These increasing trends are not as common for longer duration events (Westra and Sisson 2011).

These trends are generally unexplained. One approach that may be useful is that of Hardwick-Jones et al. (2010) who examined the relationship between observed temperature and extreme precipitation using historical precipitation records. This approach could be extended to project future changes although there are still some uncertainties with respect to the role that moisture availability plays in these relationships.

\subsection{Attribution of changes in floods}

Attribution is the process of identifying the reasons for significant changes in a climatic or hydrologic variable. This is a relatively new area of interest in hydrology and Merz et al. (2012) argue that much more rigour is required in attributing flood hazards; most studies to date have focused on detection (identifying the changes in the variable, e.g. Ishak et al. (2013)). An attribution framework needs to show that the changes are consistent with the driver of change and just as importantly that the changes are inconsistent with other alternative drivers. Finally a level of confidence in the attribution is required (Merz et al. 2012). Harrigan et al. (2014) also suggest that rather than focussing on single drivers of change, that a multiple working hypotheses framework should be adopted. Similar attribution studies have not been undertaken in Australia and this is an area of research that should be pursed. The concept of Fraction of Attributable Risk (Allen 2003) can be used to investigate the contribution of anthropogenic climate change to that a specific flood event (e.g. Pall et al. 2011). In a recent Australian example, Evans and Boyer-Souchet (2012) used an ensemble of high-resolution model simulations to examine the record rainfall totals in Queensland during the 
2010 and 2011 floods and found that higher than average sea surface temperatures to the north of

Australia contributed $25 \%$ more precipitation than average La Niña conditions.

242

243

244

245

246

247

248

249

250

251

252

253

254

255

256

257

258

259

260

261

262

263

264

One of the working hypotheses that should be considered when attributing observed changes is catchment modification. The main source of non-stationarity in catchment conditions is urbanisation, which is known to increase flooding in various ways (Shuster et al. 2005). The increase of impervious surfaces is well known, but other parts of the urban landscape, such as parks, also have lower infiltration rates. Rapid concentration of the flows leads to a shorter and more intense flood peak as well as increases in flood volume. This is an issue particularly for flash floods in small catchments with urban development.

Links and feedback mechanisms with landscape processes are also not fully understood and to date have only been explored over relatively short timescales (Beringer et al. 2011; Wu et al. 2013). In rural areas, forest clearing, bushfire and afforestation activities have a large role in changing catchment conditions and hence flood hazard. However, although a direct link has often been implied between forest cover and flooding, the impact of such activities primarily depends on the effect on soil infiltration capacity, which does not necessarily have to be directly affected by forest cover change (van Dijk and Keenan 2007). Nonetheless, analysis of changes in streamflow after large-scale tree clearing in inland Queensland did suggest a small increase in catchment flood response (Pena-Arancibia et al. 2012).

\section{Future changes to floods and causative variables}

\subsection{Future changes to floods}

Limited research has been undertaken to examine changes to future flood hazard globally (Arnell and Gosling 2014) and this is also the case within Australia. General comments on increasing risk of floods and droughts are very common, particularly in the climate change adaptation literature. However, these are typically based on the assumption that changes to rainfall extremes (see Section 4.2) will translate directly to changes in flood. IPCC (2013) and other assessments (e.g., Kundzewicz 
et al. 2013) have concluded that there is only low confidence in numerical projections of changes to flood frequency or magnitude.

Most research has considered specific catchments with a limited subset of driving climate scenarios. Some global studies have considered either large Australian catchments or used a grid-based approach with a land surface model or river routing model to estimate changes in flood magnitudes at all locations around the world. Hirabayashi et al. (2013) used discharge projections from 11 GCMs for a range of future scenarios within a global river routing model. It was found that increases in the frequency of floods are likely in northern Australia and along the east coast, whilst flood frequency was projected to decrease in south-western Western Australia. The Murray-Darling basin, which provides over $40 \%$ of Australia's agricultural output and accounts for $70 \%$ of the total irrigated area in Australia (location shown as MB in Figure 3), was projected to have increased flood magnitudes by 8 out of 11 models but the projected return periods of the current 100-year flood were found to vary from 1 year to approximately 5000 years, the highest variability seen in the 30 basins that were analysed.

Global assessments necessarily make simplifying assumptions in terms of the methods of calculating climate changes. The uncertainty introduced by using simplified hydrologic or hydraulic routing models can be as large as the climate model uncertainty (Dankers et al. 2014). Another issue is that global assessments often focus on percentage changes. However, this does not always translate into impacts of practical significance. For example, a $20 \%$ change to floods in central Australia might be much smaller increase in volume and in the number of people affected than a $5 \%$ change to floods in northern Australia or the heavily populated south-east coast.

As highlighted by Arnell and Gosling (2014), "small-scale flooding from small rivers ... is not included, and neither is flash-flooding within urban areas caused by intense rainfall" in these global assessments. In some ways, understanding flash flooding in urban catchments is a simpler task because the effects of antecedent conditions are generally smaller and therefore the change in 
floods can be more easily related to changes in the extreme rainfalls, while evapotranspiration and pre-event catchment wetness are secondary influences. However, even in this simpler situation, there has been limited catchment-scale research of potential changes to flood risk due primarily to the uncertainties in future rainfall projections discussed in the next section.

\subsection{Future changes to causative variables}

The focus of this section is on changes to rainfall extremes in Australia, firstly on the basis of projections from GCMs are discussed in the following section followed by results from downscaled climate projections.

\subsubsection{Rainfall projections from GCMs}

Plausible changes in rainfall extremes have recently been assessed as part of the revised climate change projections for Australia (CSIRO and Bureau of Meteorology 2015). Daily rainfall extremes were defined as the magnitudes associated with a 20-year return period event. The projections are available for eight regions, which provides a useful summary of the potential changes in extremes across the country, however the disadvantage is that for some of the very large regions the 20-year return value is derived as the average of grid cell estimates, obscuring sub-regional variations.

Assessments of the rainfall extremes are based on simulations from $21 \mathrm{GCMs}$ from the Coupled Model Intercomparison Project 5 archive for two Representative Concentration Pathways (RCP4.5 and 8.5) over for two future time horizons: a near future (2020-2039) and a more distant period (2080-2099). Changes are reported relative to the baseline period 1986-2005 used in IPCC (2013).. Projections for 2080-2099 in Figure 3 show very similar results across all regions, indicating that rainfall amounts associated with extreme rainfall events are likely to increase across Australia. Indeed, when comparing projected changes in annual mean rainfall, annual maximum rainfall and the 20-year return value, even in regions where mean annual rainfall is expected to decrease, the annual maximum rainfall is projected to increase. For the 2080-2099 time horizon and RCP 8.5 scenario, median changes typically suggest an increase in annual maximum rainfall of around $25 \%$. 
Potential changes to mean annual rainfall are also relevant to flood hazard as they may affect antecedent conditions in the catchment. For example, returning to the example of the MurrayDarling Basin, the multi-model median increase in rainfall extremes is much larger than the slight decrease in mean annual rainfall, providing support to the projected changes in flood hazard from Hirabayashi et al. (2013). Changes in antecedent conditions are dealt with in more detail in Kiem et al., (this issue). However as highlighted earlier, the interplay between antecedent conditions and extreme rainfall leads to a non-linear response in many catchments and can complicate the interpretation of rainfall changes with respect to flood hazard. In summary, there is high confidence that rainfall extremes will increase across most of Australia. However, there is only low confidence in the magnitude of change (CSIRO and Bureau of Meteorology 2015). The reason for this is that many of the processes associated with extreme rainfall, summarised in Westra et al. (this issue) and Walsh et al. (this issue), are poorly resolved in GCMs.

\subsubsection{Regional climate projections}

While a number of projects have used statistical and dynamical methods to downscale future climate projections over regions of Australia, few of them have explicitly looked at changes in rainfall extremes. Evans and McCabe (2013) examined future changes in moderate precipitation extremes (defined as the annual total of all days above the 99th percentile of daily precipitation) over the Murray-Darling basin and Eastern Seaboard derived from downscaling a single GCM with a single downscaling six GCMs using a single RCM ( $\sim 10 \mathrm{~km}$ resolution) over Tasmania and projected increases in maximum 1 and 5-day precipitation intensities, separated by longer dry spells. 
In contrast to these studies, Perkins et al. (2014) investigated changes in precipitation extremes

(defined as the 20- year return period) produced by an RCM with a lower resolution (60km) model that covered all of Australia. They found that the changes projected by the RCM differed from the host GCMs and did not support an increase in extreme precipitation across the entire country. These studies suggest caution should be used when relying on projections of precipitation extremes made by models that do not resolve key processes, which is a problem for GCMs and low resolution RCMs. In particular, for sub-daily precipitation extremes it has been suggested that convection-permitting resolution models are required (Kendon et al. 2014; Westra et al. 2014) but few such studies have been performed over Australia (Argüeso et al. 2013) and one should be equally cautious of projections based on single models or very small ensembles.

\section{Discussion and recommendations}

Flood hazard in Australia is expected to change in the future but at this stage it is not possible to even universally predict the direction of these changes. Trends in rainfall extremes have been explored, but work remains to be done to clarify the relative influences of temperature and moisture availability on extreme precipitation at sub-daily durations. There is some confidence in very highresolution RCM projections of extremes but these models have not yet been run over the majority of the country. In addition, there are still major gaps in explaining the direction and causes for historical flood trends and variability, and as such projections for future flood behaviour are highly uncertain.

The review of historical analyses on flood hazard shows that there is still extensive research required on how to identify and separate the influences of long-term trends from other climate cycles that occur and interact over a range of timescales. This is an important challenge with respect to precipitation, and the challenge of converting improved understanding of precipitation variability to understanding of the variability of flood hazard adds further complexity. Reliable data sets of flood records are required, similar to the coastal flood database that was recently developed for the 

national dataset, although for small catchments the daily resolution data will not capture the peak flood flow. Paleo-flood records, which extend for several hundreds of years to thousands of years, may assist in placing the instrumental records in context for very large catchments, especially those with relatively short and sparse instrumental networks. Examining the temporal variability of these flood databases will provide a useful baseline for understanding the direction of historical changes and, as discussed below, modelling studies will be needed to attribute the trends to their causes and extrapolate to the future.

There is a need for robust future projections of extreme precipitation over daily and longer durations. Such projections need to capture both the large-scale influences of various climate modes, as well as the local to regional scale processes that are the proximal cause of extreme precipitation, including phenomena such as East Coast Lows, bands of thunderstorms, interactions 
391 Continuous simulation models for rainfall and runoff are required to address this issue. Developing a

392

393

394

395

396

397

398

399

400

401

402

403

404

405

406

407

408

409

410

411

412

413

414

415 common framework for implementing such models to understand changes at the individual catchment scale could be a useful starting point. This framework could cover continuous simulation methods to address climate changes in precipitation, as well as appropriate rainfall runoff models for assessing flood risk. Another useful contribution would be to identify how long continuous sequences of rainfall and runoff data need to be to separate the impacts of natural variability in the climate system from climate change signals with respect to flood hazard in particular.

Further exploration of the relative importance of different runoff-generating mechanisms in Australian catchments, including how these mechanisms vary geographically, will be critical to help better understand the climatic controls on floods, and in particular the relative influence of antecedent moisture on flood magnitude. Insights are likely to be gained through investigation of stores and fluxes of moisture in highly instrumented experimental catchments, combined with numerical experiments such as those conducted by Mirus and Loague (2013) to assess the sensitivity of various assumptions on catchment sensitivity to changes in rainfall extremes.

Our ability to resolve processes across an ever-wider range of spatial and temporal scales, together with the increase in availability of observational data from in-situ and remotely sensed sources, suggests that substantial improvements in our ability to attribute changes to floods are possible. However, in many cases changes in flood hazard will occur because of simultaneous changes to multiple processes (including climatic and land use changes), so that the specific contribution of individual processes will remain difficult to isolate. Furthermore, there remains significant uncertainty in key driving variables such as extreme rainfall. Finally, the 'uniqueness of place' (Beven 2000) of individual catchment processes indicate that changes are likely to be geographically diverse, posing substantial challenges to continental-scale assessments of historical and future changes to flood hazard. As a result, the attribution of changes to flood hazard to specific causes remains a significant challenge. 


\section{Acknowledgements}

417 This paper was a result of collaboration through the working group 'Trends and Extremes' as part of the Australian Water and Energy Exchanges Initiative (OzEWEX). J. Evans was supported by the Australian Research Council Future Fellowship FT110100576. A. Van Dijk was supported through Australian Research Council's Discovery Projects funding scheme (project number DP40103679). S.

Westra and F. Johnson were supported through Australian Research Council's Discovery Project DP150100411. The constructive comments from the anonymous reviewers helped to improve the clarity of the paper.

\section{References}

Alexander LV, Hope P, Collins D, Trewin B, Lynch A, Nicholls N (2007) Trends in Australia's climate means and extremes: a global context Aust Meteorol Mag 56:1-18

Allen M (2003) Liability for climate change Nature 421:891-892 doi:10.1038/421891a

Argüeso D, Evans J, Fita L (2013) Precipitation bias correction of very high resolution regional climate models Hydrology \& Earth System Sciences Discussions 10

Arnell N, Gosling S (2014) The impacts of climate change on river flood risk at the global scale Climatic Change:1-15 doi:10.1007/s10584-014-1084-5

Beringer J, Hutley LB, Hacker JM, Neininger B (2011) Patterns and processes of carbon, water and energy cycles across northern Australian landscapes: from point to region Agricultural and Forest Meteorology 151:1409-1416

Beven KJ (2000) Uniqueness of place and process representations in hydrological modelling Hydrology and Earth System Sciences Discussions 4:203-213

Blöschl G et al. (2015) Increasing river floods: fiction or reality? Wiley Interdisciplinary Reviews: Water doi:doi: 10.1002/wat2.1079

Bureau of Meteorology (2015) Hydrologic Reference Stations, October 2015 edn., http://www.bom.gov.au/water/hrs/index.shtm

Callaghan J, Power SB (2014) Major coastal flooding in southeastern Australia 1860-2012, associated deaths and weather systems Australian Meteorological and Oceanographic Journal 64:183-213

Chiew FH, Piechota TC, Dracup JA, McMahon TA (1998) El Nino/Southern Oscillation and Australian rainfall, streamflow and drought: Links and potential for forecasting Journal of Hydrology 204:138-149

Cordery I (2003) A Case for Increased Collection of Water Resources Data Australian Journal of Water Resources 6:95-104 
CSIRO, Bureau of Meteorology (2015) Climate Change in Australia Projections for Australia's NRM Regions: Technical Report. CSIRO and Bureau of Meteorology, Australia

Dankers R et al. (2014) First look at changes in flood hazard in the Inter-Sectoral Impact Model Intercomparison Project ensemble Proceedings of the National Academy of Sciences 111:3257-3261 doi:10.1073/pnas.1302078110

Engineers Australia (1987) Australian Rainfall and Runoff. Engineers Australia, Canberra

Evans JP, Boyer-Souchet I (2012) Local sea surface temperatures add to extreme precipitation in northeast Australia during La Niña Geophysical Research Letters 39

Evans JP, McCabe M (2013) Effect of model resolution on a regional climate model simulation over southeast Australia Clim Res 56:131-145

Evans S, Marchand R, Ackerman T (2014) Variability of the Australian Monsoon and Precipitation Trends at Darwin Journal of Climate 27:8487-8500 doi:Doi 10.1175/Jcli-D-13-00422.1

Fischer E, Knutti R (2014) Detection of spatially aggregated changes in temperature and precipitation extremes Geophysical Research Letters 41:547-554

Gaál L, Szolgay J, Kohnová S, Parajka J, Merz R, Viglione A, Blöschl G (2012) Flood timescales: Understanding the interplay of climate and catchment processes through comparative hydrology Water Resources Research 48:n/a-n/a doi:10.1029/2011WR011509

Gallant AJ, Hennessy KJ, Risbey J (2007) Trends in rainfall indices for six Australian regions: 19102005 Aust Meteorol Mag 56:223-241

EM-DAT: International Disaster Database (2015) Université Catholique de Louvain,. www.emdat.be.

Hapuarachchi HAP, Wang QJ, Pagano TC (2011) A review of advances in flash flood forecasting Hydrological Processes 25:2771-2784 doi:Doi 10.1002/Hyp.8040

Hardwick-Jones R, Westra S, Sharma A (2010) Observed relationships between extreme sub-daily precipitation, surface temperature, and relative humidity Geophysical Research Letters 37 doi:10.1029/2010GL045081

Harrigan S, Murphy C, Hall J, Wilby R, Sweeney J (2014) Attribution of detected changes in streamflow using multiple working hypotheses Hydrology and Earth System Sciences 18:1935-1952

Hirabayashi Y et al. (2013) Global flood risk under climate change Nature Clim Change 3:816-821 doi:10.1038/nclimate1911

IPCC (2013) Climate Change 2013: The Physical Science Basis. Contribution of Working Group I to the Fifth Assessment Report of the Intergovernmental Panel on Climate Change. Cambridge University Press, Cambridge, United Kingdom and New York, NY, USA. doi:10.1017/CBO9781107415324

Ishak EH, Rahman A, Westra S, Sharma A, Kuczera G (2013) Evaluating the non-stationarity of Australian annual maximum flood Journal of Hydrology 494:134-145 doi:DOI 10.1016/j.jhydrol.2013.04.021 
Jakob D, Karoly DJ, Seed A (2011a) Non-stationarity in daily and sub-daily intense rainfall - Part 1: Sydney, Australia Nat Hazards Earth Syst Sci 11:2263-2271 doi:10.5194/nhess-11-22632011

Jakob D, Karoly DJ, Seed A (2011b) Non-stationarity in daily and sub-daily intense rainfall - Part 2: Regional assessment for sites in south-east Australia Nat Hazards Earth Syst Sci 11:22732284 doi:10.5194/nhess-11-2273-2011

Kahn ME (2005) The death toll from natural disasters: the role of income, geography, and institutions Review of economics and statistics 87:271-284

Kendon EJ, Roberts NM, Fowler HJ, Roberts MJ, Chan SC, Senior CA (2014) Heavier summer downpours with climate change revealed by weather forecast resolution model Nat Clim Change 4:570-576 doi:Doi 10.1038/Nclimate2258

Kiem AS, Franks SW, Kuczera G (2003) Muti-decadal variability of flood risk Geophysical Research Letters 30:1035 doi:10.1029/2002GL015992

Kiem AS, Verdon-Kidd DC (2013) The importance of understanding drivers of hydrocliamtic variability for robust flood risk planning in the coastal zone. Australian Journal of Water Resources $17: 126-134$

Kundzewicz ZW et al. (2013) Flood risk and climate change: global and regional perspectives Hydrological Sciences Journal 59:1-28 doi:10.1080/02626667.2013.857411

Lau WKM, Wu HT, Kim KM (2013) A canonical response of precipitation characteristics to global warming from CMIP5 models Geophysical Research Letters 40:3163-3169

Laz OU, Rahman A, Yilmaz A, Haddad K (2014) Trends in sub-hourly, sub-daily and daily extreme rainfall events in eastern Australia Journal of Water and Climate Change 5:667-675

Leonard M et al. (2014) A compound event framework for understanding extreme impacts Wiley Interdisciplinary Reviews: Climate Change 5:113-128

McKay G (2007) THE LIFE BLOOD OF FLOODS Flood Producing Weather Systems. Paper presented at the 47th Annual NSW Floodplain Management Conference, Gunnedah, 27 February - 1 March 2007

Merz B, Vorogushyn S, Uhlemann S, Delgado J, Hundecha Y (2012) HESS Opinions" More efforts and scientific rigour are needed to attribute trends in flood time series" Hydrology and Earth System Sciences 16:1379-1387

Micevski T, Franks SW, Kuczera G (2006) Multidecadal variability in coastal eastern Australian flood data Journal of Hydrology 327:219-225 doi:10.1016/j.jhydrol.2005.11.017

Mirus BB, Loague K (2013) How runoff begins (and ends): Characterizing hydrologic response at the catchment scale Water Resources Research 49:2987-3006 doi:10.1002/wrcr.20218

Pall P et al. (2011) Anthropogenic greenhouse gas contribution to flood risk in England and Wales in autumn 2000 Nature 470:382-385 doi:http://www.nature.com/nature/journal/v470/n7334/abs/10.1038-nature09762unlocked.html\#supplementary-information 
Pena-Arancibia JL, Dijk AIJMv, Guerschman JP, Mulligan M, Bruijnzeel LA, McVicar TR, van Dijk AIJM (2012) Detecting changes in streamflow after partial woodland clearing in two large catchments in the seasonal tropics. Journal of Hydrology (Amsterdam) 416/417:60-71 doi:10.1016/j.jhydrol.2011.11.036

Perkins SE, Moise A, Whetton P, Katzfey J (2014) Regional changes of climate extremes over Australia - a comparison of regional dynamical downscaling and global climate model simulations International Journal of Climatology 34:3456-3478 doi:DOI 10.1002/joc.3927

Power S, Casey T, Folland CK, Colman A, Mehta V (1999) Inter-decadal modulation of the impact of ENSO on Australia Climate Dynamics 15:319-324

Risbey JS, Pook MJ, Mclntosh PC, Wheeler MC, Hendon HH (2009) On the remote drivers of rainfall variability in Australia Monthly Weather Review 137:3233-3253

Rouillard A, Skrzypek G, Dogramaci S, Turney C, Grierson P (2015) Impacts of high inter-annual variability of rainfall on a century of extreme hydrologic regime of northwest Australia Hydrology and Earth System Sciences 19:2057-2078

Shi G, Cai W, Cowan T, Ribbe J, Rotstayn L, Dix M (2008) Variability and Trend of North West Australia Rainfall: Observations and Coupled Climate Modeling Journal of Climate 21:2938-2959

Shuster WD, Bonta J, Thurston H, Warnemuende E, Smith DR (2005) Impacts of impervious surface on watershed hydrology: A review Urban Water Journal 2:263-275 doi:10.1080/15730620500386529

Trancoso R, Larsen JR, McAlpine C, McVicar TR, Phinn S (2016) Linking the Budyko framework and the Dunne diagram Journal of Hydrology 535:581-597

van Dijk AIJM et al. (2013) The Millennium Drought in southeast Australia (2001-2009): Natural and human causes and implications for water resources, ecosystems, economy, and society Water Resources Research 49:1040-1057 doi:10.1002/wrcr.20123

van Dijk AIJM, Keenan RJ (2007) Planted forests and water in perspective Forest Ecology and Management 251:1-9 doi:10.1016/j.foreco.2007.06.010

Verdon DC, Wyatt AM, Kiem AS, Franks SW (2004) Multidecadal variability of rainfall and streamflow: Eastern Australia Water Resources Research 40 doi:10.1029/2004wr003234

Ward PJ, Jongman B, Kummu M, Dettinger MD, Weiland FCS, Winsemius HC (2014) Strong influence of El Niño Southern Oscillation on flood risk around the world Proceedings of the National Academy of Sciences 111:15659-15664

Westra S, Alexander LV, Zwiers FW (2013) Global Increasing Trends in Annual Maximum Daily Precipitation Journal of Climate 26:3904-3918 doi:Doi 10.1175/Jcli-D-12-00502.1

Westra S et al. (2014) Future changes to the intensity and frequency of short-duration extreme rainfall Reviews of Geophysics 52:522-555 doi:Doi 10.1002/2014rg000464

Westra S, Sisson SA (2011) Detection of non-stationarity in precipitation extremes using a max-stable process model Journal of Hydrology 406:119-128 doi:DOI 10.1016/j.jhydrol.2011.06.014 
563

564

565

566

567 568 (1)
Wu P, Christidis N, Stott P (2013) Anthropogenic impact on Earth/'s hydrological cycle Nat Clim Change 3:807-810

Yilmaz A, Perera B (2013) Extreme rainfall nonstationarity investigation and intensity-frequencyduration relationship Journal of Hydrologic Engineering 19:1160-1172 


\section{Figure Captions}

570 Figure 1: Major Interactions between flood processes on different timescales (after Gaál et al.,

571 2012). $T_{p}$ is the period over which the flood producing rainfall occurs depicted here using a rainfall

572 hyetograph and can be significantly shorter than the flood duration $\left(T_{q}\right)$. Both $T_{p}$ and $T_{q}$ are affected

573 by the longer timescale processes shown here at synoptic, seasonal, climate and geological scales.

574 Figure 2: Conceptual representation of runoff generation processes relating to floods. Red highlights

575 water fluxes during the event, and orange highlights antecedent water fluxes over a longer time

576 period, with arrow sizes proportional to flux magnitude. (a) Saturation excess flow where the 577 overland flow is proportional to the area of the catchment fully saturated. A longer term water 578 balance determines the initial degree of catchment saturation and the event determines the growth

579 in the saturated area. (b) Infiltration excess where the initial degree of infiltration depends on antecedent rainfall. The overland flow is proportional to excess rainfall and infiltration diminishes during the event.

Figure 3: Bars showing median and the 10th to 90th percentile range of projected change in daily rainfall for 2080-2099 relative to 1986-2005 for RCP8.5. Each box shows from left: (a) annual mean rainfall based on a set of 39 models and from a consistent subset of 21 CMIP5 models the (b) annual mean rainfall, (c) annual maximum daily rainfall, and (d) 20 year return level of the annual wettest day rainfall. Blue indicates increase and brown indicates decrease. The Australia average results are shown in the bottom left. Reprint from Figure 7.2.13 in CSIRO and Bureau of Meteorology (2015) 


\section{Figures}

2

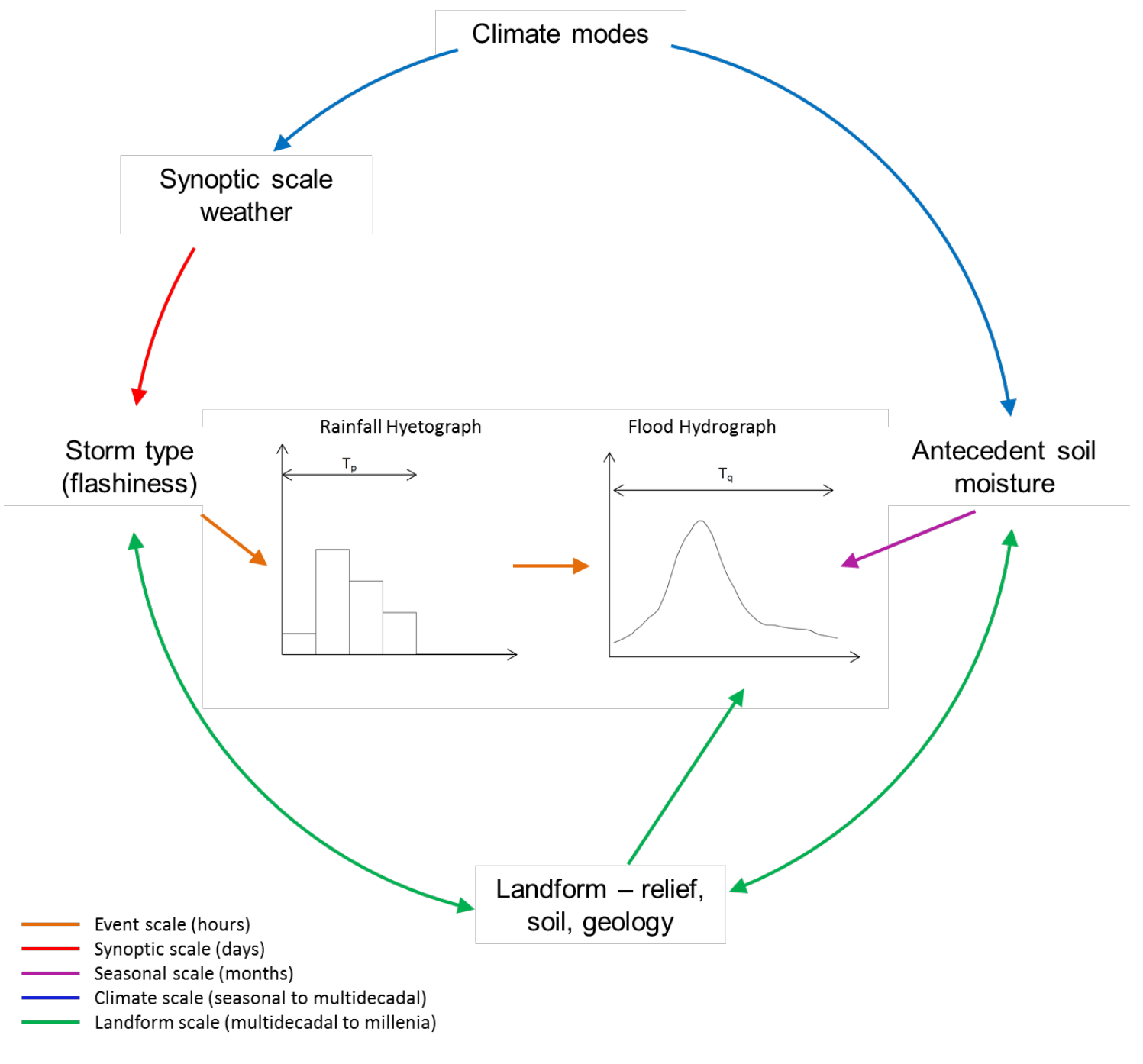

$4 \quad$ Figure 1: Major Interactions between flood processes on different timescales (after Gaál et al., 2012;

5 Merz et al., 2014). $T_{p}$ is the period over which the flood producing rainfall occurs depicted here using

6 a rainfall hyetograph. This period can be significantly shorter than the period over which the flood

7 itself occurs $\left(T_{q}\right)$. Both $T_{p}$ and $T_{q}$ are affected by the longer timescale processes shown here at synoptic, seasonal, climate and geological scales. 

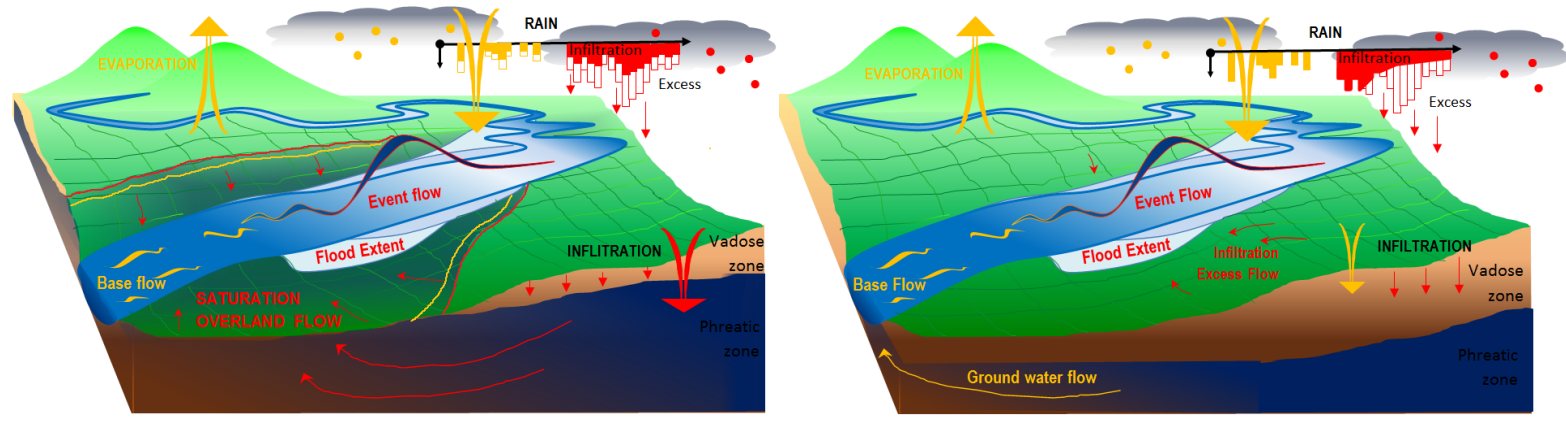

12 Figure 2: Conceptual representation of runoff generation processes relating to floods. Red highlights

13 water fluxes over the event timescale, and orange highlights antecedent water fluxes over a longer

14 time period, with arrow sizes depicted as being proportional to flux magnitude. (a) Saturation excess

15 flow where the overland flow is proportional to the area of the catchment fully saturated, where a

16 longer term water balance to determine the initial degree of catchment saturation and where the

17 event determines the growth in the saturated area (b) Infiltration excess where the initial degree of

18 infiltration depends on antecedent rainfall and the overland flow is proportional to the degree of excess rainfall, where infiltration diminishes over the scale of the event. 


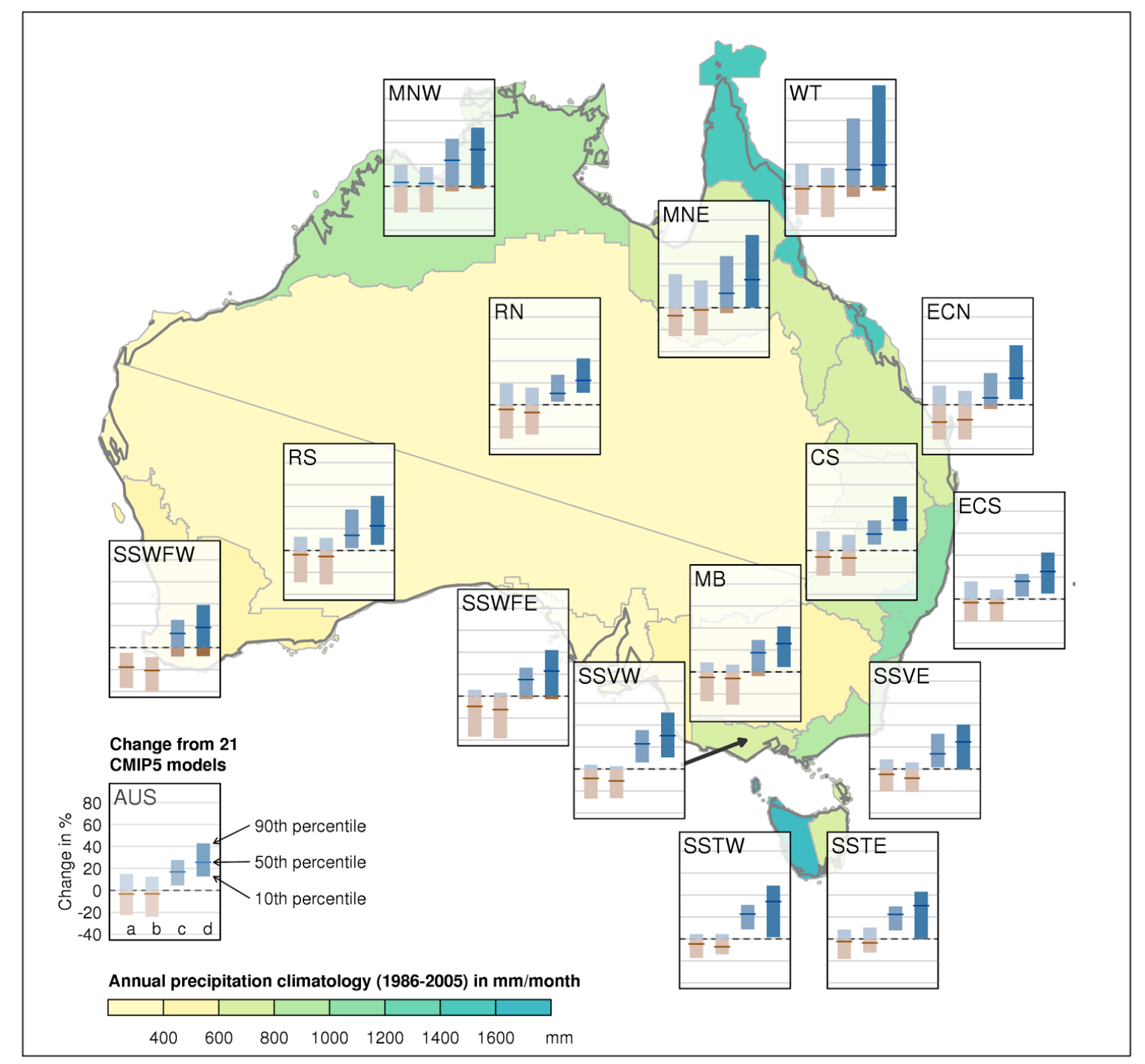

22 Figure 3: Bars showing median and extent of the 10th to 90th percentile range of projected change

23 in daily rainfall for 2080-2099 relative to 1986-2005 for RCP8.5. Each box shows from the left: (a)

24 annual mean rainfall based on a set of 39 models and from a consistent subset of 21 CMIP5 models

25 the (b) annual mean rainfall, (c) the annual maximum daily rainfall, and (d) the 20 year return level

of the annual wettest day rainfall as calculated. Blue indicates increase and brown indicates

27 decrease. The Australia average results are shown in the bottom left. Reprint from Figure 7.2.13 in

CSIRO and Bureau of Meteorology (2015) 